\title{
Inhibition of fatty acid synthase in melanoma cells activates the intrinsic pathway of apoptosis
}

\author{
Karina G Zecchin ${ }^{1,2}$, Franco A Rossato², Helena F Raposo ${ }^{3}$, Daniela R Melo², Luciane C Alberici ${ }^{4}$, \\ Helena CF Oliveira ${ }^{3}$, Roger F Castilho ${ }^{2}$, Ricardo D Coletta ${ }^{1}$, Aníbal E Vercesi ${ }^{2}$ and Edgard Graner $^{1}$
}

Fatty acid synthase (FASN) is the metabolic enzyme responsible for the endogenous synthesis of the saturated long-chain fatty acid, palmitate. In contrast to most normal cells, FASN is overexpressed in a variety of human cancers, including cutaneous melanoma, in which its levels of expression are associated with tumor invasion and poor prognosis. We have previously shown that FASN inhibition with orlistat significantly reduces the number of spontaneous mediastinal lymph node metastases following the implantation of B16-F10 mouse melanoma cells in the peritoneal cavity of C57BL/6 mice. In this study, we investigate the biological mechanisms responsible for the FASN inhibition-induced apoptosis in B16-F10 cells. Both FASN inhibitors, cerulenin and orlistat, significantly reduced melanoma cell proliferation and activated the intrinsic pathway of apoptosis, as demonstrated by the cytochrome $c$ release and caspase- 9 and -3 activation. Further, apoptosis was preceded by an increase in both reactive oxygen species production and cytosolic calcium concentrations and independent of p53 activation and mitochondrial permeability transition. Taken together, these findings demonstrate the mitochondrial involvement in FASN inhibition-induced apoptosis in melanoma cells.

Laboratory Investigation (2011) 91, 232-240; doi:10.1038/labinvest.2010.157; published online 30 August 2010

KEYWORDS: apoptosis; B16-F10 cells; cerulenin; fatty acid synthase; melanoma; orlistat

Fatty acid synthase (FASN, EC2. 3.1.85) is the anabolic multifunctional enzyme responsible for endogenous fatty acid synthesis from the small carbon precursors acetyl-CoA and malonyl-CoA. ${ }^{1,2}$ FASN is structurally arranged as a homodimer and each $\sim 250 \mathrm{kDa}$ polypeptide chain contains seven distinct catalytic sites that sequentially act to generate the 16 -carbon saturated fatty acid palmitate. ${ }^{1,3}$ FASN is downregulated in most normal cells, except in lipogenic tissues as liver, lactating breast, fetal lung and adipose tissue. ${ }^{4,5}$ Conversely, the overexpression of FASN in several human malignancies, such as those of prostate, breast, ovary, melanoma, and soft tissue sarcomas ${ }^{6-19}$ has been associated with poor prognosis. FASN inhibition reduces cell proliferation by blocking DNA replication during S-phase, induces apoptosis, ${ }^{20-23}$ and decrease the size of prostate, ovarian, and breast cancer xenografts. ${ }^{7,8,24}$ Moreover, the inhibition of FASN activity is chemopreventive in the neu-N mouse model for breast cancer. ${ }^{25}$
The biological mechanisms responsible for the FASN inhibition-induced apoptosis are still not clear. The extrinsic pathway of apoptosis triggered by death domains was described in breast cancer cells because of the accumulation of malonyl-CoA and ceramide after FASN silencing with siRNA. ${ }^{26}$ Mitochondrial involvement, evidenced by increased levels of the pro-apoptotic protein Bax and cytochrome $c$ release, was shown in tumor cell lines following pharmacological FASN inhibition. ${ }^{27,28}$ Despite the fact that the expression of a dominant-negative mutant p53 increases sensitivity of colon carcinoma cells to FASN inhibitors, ${ }^{22}$ FASN inhibition-induced apoptosis was described as p53 independent. ${ }^{27}$

Malignant melanoma is a chemotherapy-resistant aggressive tumor derived from melanocytes of the skin and, less frequently, oral mucosal membranes. In the last decades, its incidence is increasing in the United States, with more than 68000 new cases estimated for 2009 according to American

\footnotetext{
'Departamento de Diagnóstico Oral, Faculdade de Odontologia de Piracicaba, Universidade Estadual de Campinas (UNICAMP), Piracicaba, São Paulo, Brazil; ${ }^{2}$ Departamento de Patologia Clínica, Faculdade de Ciências Médicas, Universidade Estadual de Campinas (UNICAMP), Campinas, São Paulo, Brazil; ${ }^{3}$ Departamento de Fisiologia e Biofísica, Instituto de Biologia, Universidade Estadual de Campinas (UNICAMP), Campinas, São Paulo, Brazil and ${ }^{4}$ Departamento de Química e Física, Faculdade de Ciências Farmacêuticas de Ribeirão Preto, Universidade de São Paulo (USP), Ribeirão Preto, São Paulo, Brazil

Correspondence: Dr E Graner, Departamento de Diagnóstico Oral, Faculdade de Odontologia de Piracicaba, Universidade Estadual de Campinas (UNICAMP); Avenida Limeira 901, CP 52, Areão, Piracicaba, São Paulo 13414-018, Brazil.

E-mail: egraner@fop.unicamp.br

Received 4 February 2010; revised 17 June 2010; accepted 16 July 2010
} 
Cancer Society. Moreover, FASN immunohistochemical expression in cutaneous melanoma was clearly associated with Breslow thickness and predicted poor prognosis. ${ }^{12,16}$ We have recently shown that the inhibition of FASN activity with the anti-obesity drug orlistat significantly reduced proliferation and promoted apoptosis in the mouse metastatic melanoma cell line B16-F10. ${ }^{29}$ In this study, we show that FASN inhibition activates the intrinsic pathway of apoptosis in B16-F10 cells by cytochrome $c$ release and caspase- 9 and -3 activation, which were preceded by increased reactive oxygen species (ROS) production and cytosolic calcium concentration. p53 activation and the mitochondrial permeability transition (MPT) were not involved in the orlistat- or cerulenin-induced apoptotic cell death.

\section{MATERIALS AND METHODS Cell Culture}

B16-F10 cells were obtained from American Type Culture Collection, USA and cultured in RPMI (Vitrocell, Brazil) supplemented with 1 or $10 \%$ fetal bovine serum (Vitrocell), $100 \mu \mathrm{g} / \mathrm{ml}$ gentamycin (Vitrocell), $100 \mathrm{IU} / \mathrm{ml}$ penicillin (Vitrocell), and $100 \mathrm{mg} / \mathrm{ml}$ streptomycin (Vitrocell) at $37^{\circ} \mathrm{C}$ in a humidified atmosphere with $5 \% \mathrm{CO}_{2}$. To block FASN activity, cerulenin (Sigma-Aldrich, USA) or orlistat (Roche, Switzerland) were added to the culture medium at the concentrations described in the figure legends. Orlistat was extracted from Xenical capsules as previously described. ${ }^{30}$

\section{Determination of Cell Viability and Proliferation}

To determine the anti-proliferative and cytotoxic effects of cerulenin and orlistat, cells were stained with $0.1 \%$ trypan blue and counted in a Neubauer chamber. Viability was determined by exclusion of stained cells. Cell viability was also determined by 3-(4,5-dimethylthiazol-2-yl)-2,5-diphenyltetrazolium bromide assay (MTT, Sigma). Briefly, B16-F10 cells were plated in 6-well culture plates $\left(3-4 \times 10^{4}\right.$ cells per well) and after $24 \mathrm{~h}$, the medium was replaced by fresh medium containing FASN inhibitors. After further 24 or $48 \mathrm{~h}$, cells were washed in PBS, trypsinyzed and incubated with $2.5 \mathrm{mg} / \mathrm{ml}$ of MTT in PBS at $37^{\circ} \mathrm{C}$ for $1.5 \mathrm{~h}$. Cell pellets were dissolved with $10 \%$ SDS in $0.01 \mathrm{M} \mathrm{HCl}$ for $15 \mathrm{~min}$, centrifuged at $800 \mathrm{~g}$ for $5 \mathrm{~min}$, and the supernatants transferred to 96-well plates. The absorbance was determined with the aid of a microplate reader (Bio-Rad, USA) at $540 \mathrm{~nm}$ and cell viability expressed as the percentage of viable cells relative to the controls.

\section{Total Lipid Biosynthesis}

B16-F10 cells $\left(10^{6}\right)$ were treated with cerulenin or orlistat for $6 \mathrm{~h}$ and resuspended in $1 \mathrm{ml}$ of RPMI containing 10 or $1 \%$ fetal bovine serum, respectively, and $1 \mathrm{mCi}$ of $\left[{ }^{3} \mathrm{H}\right]$ water (Amersham Pharmacia Biotech, USA). The flasks were gassed with $\mathrm{O}_{2} / \mathrm{CO}_{2}$, sealed with stoppers, and incubated for $60 \mathrm{~min}$ at $37^{\circ} \mathrm{C}$ in a shaking water bath. Lipid extractions were performed by the addition of methanol-chloroform 2:1
$(3.75 \mathrm{ml})$ and agitation during $30 \mathrm{~min}$ at room temperature. The mixtures were centrifuged at $10000 \mathrm{~g}$ for $15 \mathrm{~min}$, the supernatants saved and the protein pellets ressuspended in $1 \mathrm{ml}$ of PBS. The procedure was repeated and combined extracts were diluted in $5 \mathrm{ml}$ of chloroform-water mixture (1:1), acidified to $\mathrm{pH} 3.0-4.0$ with $\mathrm{HCl}$ and centrifuged as described earlier. The chloroform layer was removed and saved, and the aqueous layer again extracted with the same volume of chloroform. The combined chloroform extracts were evaporated and the lipogenesis determined in $1 \mathrm{ml}$ of scintillation solution, as previously described. ${ }^{29}$

\section{Analysis of Cell Death and Cell Cycle}

Samples were analyzed in a FACSCalibur flow cytometer (BD Biosciences, USA) equipped with an argon laser and CellQuest software (version 4.1). Seven to ten thousand events were acquired for each sample. B16-F10 populations were identified by their light-scattering characteristics, enclosed in electronic gates, and analyzed for the intensity of the fluorescent probes signal.

For the analysis of cell death, cells $\left(10^{6}\right)$ were washed with PBS and resuspended in a binding buffer $(10 \mathrm{mM}$ HEPES $\mathrm{pH}$ 7.4, $150 \mathrm{mM} \mathrm{NaCl}, 5 \mathrm{mM} \mathrm{KCl}, 1 \mathrm{mM} \mathrm{MgCl}_{2}$, and $1.8 \mathrm{mM}$ $\mathrm{CaCl}_{2}$ ) containing annexin V-FITC (1:500, Invitrogen, USA) and 7-AAD $(20 \mu \mathrm{g} / \mu \mathrm{l}, 7$-Amino-actinomycin D, Molecular Probes, USA). After $20 \mathrm{~min}$ of incubation at room temperature in the dark, cells were also stained with propidium iodide (1:50, Sigma). Apoptosis was quantified by flow cytometry as the number of annexin V-FITC-positive and 7-AAD-negative cells, and necrosis as the number of 7-AADpositive and annexin V-FITC-negative cells, both divided by the total number of cells. Autophagy was detected by the quantification of acidic vesicular organelles. ${ }^{31}$ Briefly, cells $\left(10^{6}\right)$ were washed with PBS, stained with acridine orange (100 $\mu \mathrm{g} / \mathrm{ml}$, Sigma) for $15 \mathrm{~min}$, washed again, resuspended in PBS, and analyzed by flow cytometry.

Cell-cycle analysis was performed as previously described. ${ }^{29}$ B16-F10 cells were seeded in 6-well culture plates (3-4 $\times 10^{4}$ cells) and after $24 \mathrm{~h}$ serum starved for the same period of time. The medium was replaced by fresh medium containing FASN inhibitors and cells incubated for more 24 or $48 \mathrm{~h}$, harvested and fixed in cold $70 \%$ ethanol. Cells were then washed in PBS, treated with $10 \mu \mathrm{g} / \mathrm{ml}$ of RNAse during $1 \mathrm{~h}$ at $37^{\circ} \mathrm{C}$ and stained with $50 \mu \mathrm{g} / \mathrm{ml}$ of propidium iodide (Sigma) during $2 \mathrm{~h}$ at $4^{\circ} \mathrm{C}$. The distribution of cells in the cell cycle was analyzed by flow cytometry. Cell-cycle phases were analyzed using ModFit LT (Verity Software House, USA).

\section{Measurement of ROS}

Following the treatment with cerulenin or orlistat for $6 \mathrm{~h}$, cells $\left(10^{6}\right)$ were incubated with $3 \mu \mathrm{M} \mathrm{H}_{2}$ DCF-DA (Molecular Probes) at $37^{\circ} \mathrm{C}$ for $45 \mathrm{~min}$ or $3 \mu \mathrm{M}$ MitoSox (Molecular Probes) at $37^{\circ} \mathrm{C}$ for $10 \mathrm{~min}$, to detect cytosolic hydrogen 
peroxide $^{32}$ or mitochondrial superoxide, ${ }^{33}$ respectively. ROS levels were analyzed by flow cytometry.

\section{Measurement of Cytosolic Free $\mathrm{Ca}^{2+}$ Concentrations $\left(\left[\mathrm{Ca}^{2+}\right]_{\text {cyt }}\right)$}

After the treatment with FASN inhibitors as described above, cells $\left(10^{6}\right)$ were loaded with $3 \mu \mathrm{M}$ Fluo-3AM fluorescent probe (Molecular Probes) in the presence of $1 \mu \mathrm{M}$ pluronic acid F-127 (Molecular Probes) and $30 \mu \mathrm{g} / \mathrm{ml} \mathrm{BSA} \mathrm{(Sigma)} \mathrm{at}$ $37^{\circ} \mathrm{C}$ in a humidified atmosphere of $5 \% \mathrm{CO}_{2}$ for $40 \mathrm{~min}$. Nonhydrolyzed Fluo-3AM was removed by washing the cells in their respective medium just before acquisition of fluorescence by flow cytometry. ${ }^{34}$ Calibration was performed at the end of each experiment. $\left[\mathrm{Ca}^{2+}\right]_{\text {cyt }}$ was calculated considering $K_{\mathrm{d}}$ of the $\mathrm{Ca}^{2+}$-Fluo-3 complex $390 \mathrm{nM}^{35}$

\section{Detection of Cytochrome c Release}

After 12 or $24 \mathrm{~h}$ of treatment with cerulenin or orlistat, respectively, $10^{6}$ cells were washed with PBS and cytochrome $c$ release was analyzed by ELISA (Quantikine Rat/Mouse Cytochrome $c$ Immunoassay, R\&D Systems, USA) and by flow cytometry. Cytosolic fractions were obtained as described before $^{36}$ with few modifications. Briefly, cells were homogenized in a buffer containing $250 \mathrm{mM}$ sucrose, $2 \mathrm{mM}$ EDTA, $1 \mathrm{mg} / \mathrm{ml} \mathrm{BSA}, 50 \mu \mathrm{g} / \mathrm{ml}$ phenylmethylsulfonyl fluoride, and $2 \mu \mathrm{g} / \mathrm{ml}$ aprotinin, $\mathrm{pH} 7.4$ on ice, using a glass Dounce (\#19). Homogenates were centrifuged at $14000 \mathrm{~g}$ for $20 \mathrm{~min}$ at $4^{\circ} \mathrm{C}$ and $50 \mu \mathrm{l}$ of the supernatants containing the cytosolic fractions were transferred to ELISA plates. The absence of mitochondria in the cytosolic fractions used for cytochrome $c$ detection by ELISA was confirmed by measuring citrate synthase activity in the homogenates and supernatants. The conversion of oxaloacetate and acetyl-Coa to citrate and $\mathrm{SH}-\mathrm{CoA}$, catalyzed by citrate synthase, was monitored by measuring the colorimetric product thionitrobenzoic acid. ${ }^{37}$ Cytosolic fractions were incubated at $37^{\circ} \mathrm{C}$, in a buffer containing $50 \mathrm{mM}$ Tris- $\mathrm{HCl}(\mathrm{pH} 8.0), 0.1 \%$ Triton $\mathrm{X}-100,250 \mu \mathrm{M}$ oxaloacetate, $50 \mu \mathrm{M}$ acetyl-CoA, and $100 \mu \mathrm{M}$ 5,5'-dithiobis-(2-nitrobenzoic acid). The increase in absorbance at $412 \mathrm{~nm}$ was accompanied for $8 \mathrm{~min}$. To detect cytochrome $c$ release by flow cytometry, cells were resuspended in $1 \mathrm{ml}$ of mitochondrial medium $(125 \mathrm{mM}$ sucrose, $65 \mathrm{mM}$ $\mathrm{KCl}, 10 \mathrm{mM}$ HEPES buffer, pH 7.2, $0.5 \mathrm{mM}$ EGTA, $1 \mathrm{mM}$ $\mathrm{MgCl}_{2}$, and $2 \mathrm{mM} \mathrm{KH}_{2} \mathrm{PO}_{4}$ ) supplemented with $1 \%$ protease inhibitors mix and $1 \mathrm{mM}$ phenylmethylsulfonyl fluoride and permeabilized with $0.0005 \%$ digitonin. Pellets were resuspended in $0.5 \mathrm{ml}$ of $4 \%$ paraformaldehyde in PBS and incubated for $20 \mathrm{~min}$ at room temperature. After two washes with PBS, cells were incubated in $0.5 \mathrm{ml}$ of labeling medium ( $2 \%$ fetal bovine serum, $0.2 \%$ sodium azide, and $0.5 \%$ Triton $\mathrm{X}-100$ in PBS) for $15 \mathrm{~min}$, centrifuged at $3000 \mathrm{~g}$ for $5 \mathrm{~min}$, and then incubated with anti-cytochrome $c(1: 500,6$ H2.B4, Promega, USA) at $4^{\circ} \mathrm{C}$ for $1 \mathrm{~h}$. Cells were then washed twice in the same medium and incubated with anti-mouse-FITC (1:200, Vector Laboratories, USA) at $4^{\circ} \mathrm{C}$ for $1 \mathrm{~h}$. Cells were washed again as described above, resuspended in PBS, and analyzed by flow cytometry as described elsewhere. ${ }^{38}$

\section{Detection of Caspase-3 Activation}

Caspase- 3 activation was measured by the incubation of $10^{6}$ cells with FITC-DEVD-FMK (1:300, Calbiochem, USA) in serum-free medium for $40 \mathrm{~min}$ at $37^{\circ} \mathrm{C}$ in a humidified atmosphere with $5 \% \mathrm{CO}_{2}$. After a washing step according to the manufacturer instructions, cells were resuspended in the same medium and analyzed by flow cytometry, as described before. $^{29}$

\section{Detection of Caspase-9 and -8 Activities}

Treated cells $\left(3 \times 10^{6}\right.$ cells $)$ were resuspended in $0.2 \mathrm{ml}$ of chilled lysis buffer $(20 \mathrm{mM}$ HEPES $\mathrm{pH} 7.5,10 \mathrm{mM} \mathrm{KCl}$, $250 \mathrm{mM}$ sucrose, $2 \mathrm{mM} \mathrm{MgCl}$, and $1 \mathrm{mM}$ EDTA) containing $0.5 \mathrm{mM}$ DTT. Cell suspensions were sonicated (Mosonix Sonicator S-3000, New Highway Farmingdale, USA) and frozen at $-80^{\circ} \mathrm{C}$. Cell lysates were thawed, centrifuged at $15000 \mathrm{~g}$ for $30 \mathrm{~min}$, and the supernatants added to $0.2 \mathrm{ml}$ of reaction buffer $(25 \mathrm{mM}$ HEPES pH 7.5, 10\% sucrose, and $0.1 \%$ CHAPS) containing $10 \mathrm{mM}$ DTT. The reactions were initiated by addition of $0.1 \mathrm{mM}$ Ac-LETD-AFC (Sigma) or $0.2 \mathrm{mM}$ LEHD-pnitroanilide (Calbiochem) substrates for caspase- 8 or -9 , respectively, and incubated for $1.5 \mathrm{~h}$ at $37^{\circ} \mathrm{C}$. Caspase- 8 activity was measured by the fluorescence of free AFC using a Hitachi F4500 spectrofluorometer (Hitachi High-Tech, Japan) with excitation and emission wavelengths of 400 and $505 \mathrm{~nm}$, respectively, and slit widths of $5.0 \mathrm{~nm}$. B16-F10 melanoma cells treated with $10 \mu \mathrm{g} / \mathrm{ml}$ cycloheximide (Sigma) and $10 \mathrm{nM}$ tumor necrosis factor $\alpha$ (TNF $\alpha$, Peprotech, USA) for $20 \mathrm{~h}$ were used as a positive controls. Caspase- 9 activity was measured by the fluorescence of free pnitroanilide using a Varian Cary 50 spectrophotometer (Biocompare, USA) at $405 \mathrm{~nm}$.

\section{RNA Interference (RNAi)-Mediated Silencing of FASN Expression}

The 25-mer RNA molecules were chemically synthesized, annealed and purified by the manufacturer (Stealth RNAi, Invitrogen). Three sequences targeting Mus musculus FASN (NM_00798) were used, corresponding to nucleotides 940-964 (5'-CAATGATGGCCAACCGGCTCTCTTT- $\left.3^{\prime}\right)$, 3408-3432 (5'-TGGGAAGACCCGAACTCCAAGTTAT- $\left.3^{\prime}\right)$ and 5841-5865 (5'-CCTCTGGGCATGGCTATCTTCTTGA-3'). B16-F10 cells grown to $50 \%$ confluence were transfected with $200 \mathrm{nM}$ of a mixture containing equal parts of the FASN siRNAs using a liposome method according to manufacturer's instructions (Lipofectamine 2000, $3 \mu \mathrm{l} / \mathrm{ml}$, Invitrogen). As negative controls, cells were transfected with equimolar concentrations of a nonspecific control oligo (Stealth RNAi Negative Control Duplexes, Medium GC Duplex, Invitrogen). Transfections were performed in $60 \mathrm{~mm}$ dishes and after $72 \mathrm{~h}$ cells were collected for assessing FASN knockdown and cytochrome $c$ release. FASN knockdown 
was confirmed by western blotting with approximately $40 \mu \mathrm{g}$ of the protein lysates and antibodies against FASN (BD Biosciences, 1:3000) or beta actin (AC-15, Sigma, 1:40 000) as loading controls. Reactions were developed with an enhanced chemiluminescence detection system (ECL detection kit, Amersham Pharmacia Biotech, USA) according to manufacturer's instructions.

\section{Statistical Analysis}

The results from at least three independent experiments, each performed in duplicate or triplicate, are displayed as means \pm s.e.m. Comparisons between groups were performed using one-way Analysis of Variance with Tukey's post-hoc analysis. The level of significance was set at $P<0.05$. All data were analyzed using SigmaStat software, version 3.5 (Systat Software, USA).

\section{RESULTS}

\section{FASN Inhibitors Decrease Proliferation and Induce} B16-F10 Cell Death in a Dose-Dependent Manner

The treatment of B16-F10 cells with increasing concentrations of cerulenin or orlistat significantly reduced cell proliferation (Figures 1a, c and 2b, e) and promoted cell death (Figures $1 \mathrm{~b}$ and $\mathrm{d}$ ) as a result of the inhibition of FASN activity (Figures 2a and d). Orlistat was apparently less effective than cerulenin and the lack of cytotoxicity observed at $100 \mu \mathrm{M}$ in Figure 1c may be explained, at least in part, by the low sensitivity of the trypan blue staining in comparison with the MTT assays depicted in Figure 1d. To better characterize the FASN inhibition-induced cell death we next analyzed the rates of apoptosis, necrosis, and authophagy, by annexin $\mathrm{V}$ and 7-AAD staining, and detection of acidic vesicular organelles with acridine orange. Figures $2 \mathrm{c}$ and $\mathrm{f}$

demonstrate that high rates of apoptosis were found with the same concentrations of cerulenin and orlistat that efficiently impaired FASN activity (Figures $2 \mathrm{a}$ and $\mathrm{d}$ ). It is worth noting that the effects of orlistat at 30 and $100 \mu \mathrm{M}$ on cell cycle and apoptosis (Figures 2e and f) were observed after $48 \mathrm{~h}$, when FASN inhibition probably achieved higher levels than at $6 \mathrm{~h}$ as depicted in Figure 2d. Necrosis (Figures 2c and f) and authophagy (data not shown) levels were not significantly changed within the same experimental conditions.

\section{Increased ROS Production and Elevation of $\left[\mathrm{Ca}^{2+}\right]_{\text {cyt }}$ Precedes FASN Inhibition-Induced Apoptosis in B16-F10 Cells}

To better understand the mechanisms involved in the apoptotic cell death elicited by FASN inhibition, we analyzed the production of cytosolic and mitochondrial ROS after a $6 \mathrm{~h}$ incubation in the presence of cerulenin or orlistat. It is interesting that the treatment with orlistat promoted a twofold increase of both cytosolic hydrogen peroxide and mitochondrial superoxide levels, which were not modified by cerulenin (Figures 3a and b). Apoptosis induced by both compounds was also preceded by a substantial increase in the cytosolic levels of calcium $\left(\left[\mathrm{Ca}^{2+}\right]_{\text {cyt }}\right)$ (Figure $3 \mathrm{c}$ ). Taken together, these findings demonstrate that orlistat-induced apoptosis is preceded by increased ROS production and both orlistat- and cerulenin-apoptosis take place after an elevation of $\left[\mathrm{Ca}^{2+}\right]_{\text {cyt }}$ in melanoma cells.

\section{FASN Inhibitors Activate the Intrinsic Pathway of Apoptosis in B16-F10 Cells}

To assess the role of mitochondria in the apoptotic cell death that follows FASN chemical blockage, we first detected increased levels of cytochrome $c$ in the cytosolic fractions of
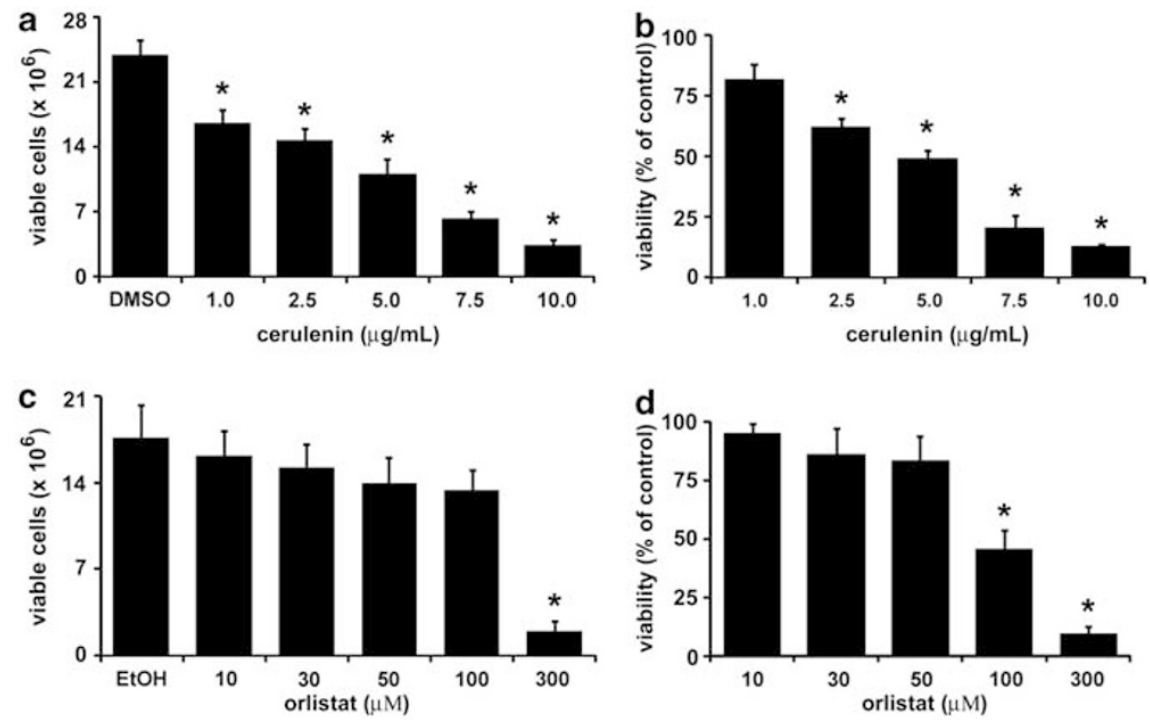

Figure 1 FASN inhibitors reduce B16-F10 melanoma cell viability. B16-F10 cells were treated with increasing concentrations of cerulenin or orlistat for 24 or $48 \mathrm{~h}$, respectively; the number of viable cells were determined using trypan blue (a and c) or the MTT assay (b and $\mathbf{~ d ) . ~ V a l u e s ~ a r e ~ m e a n ~} \pm$ s.e.m. of seven independent experiments. ${ }^{*}$ Significantly different from control at $P<0.05$ level, Student's $t$-test. 
B16-F10 cells by ELISA (Figure 4a). The absence of mitochondria in these fractions was verified by the lack of activity of the mitochondrial matrix enzyme citrate synthase, in comparison with the whole homogenates (Figure $4 \mathrm{~b}$ ). These findings were further confirmed by flow cytometry experi- ments, which showed approximately $35 \%$ of cytochrome $c$ release after treatment with both FASN inhibitors (Figures $4 \mathrm{c}$ and $\mathrm{d}$ ). In fact, siRNA specific for FASN resulted in $23 \%$ of cytochrome $c$ release from mitochondria (Figures $4 \mathrm{c}$ and $\mathrm{d}$ ) and confirmed the activation of the intrinsic
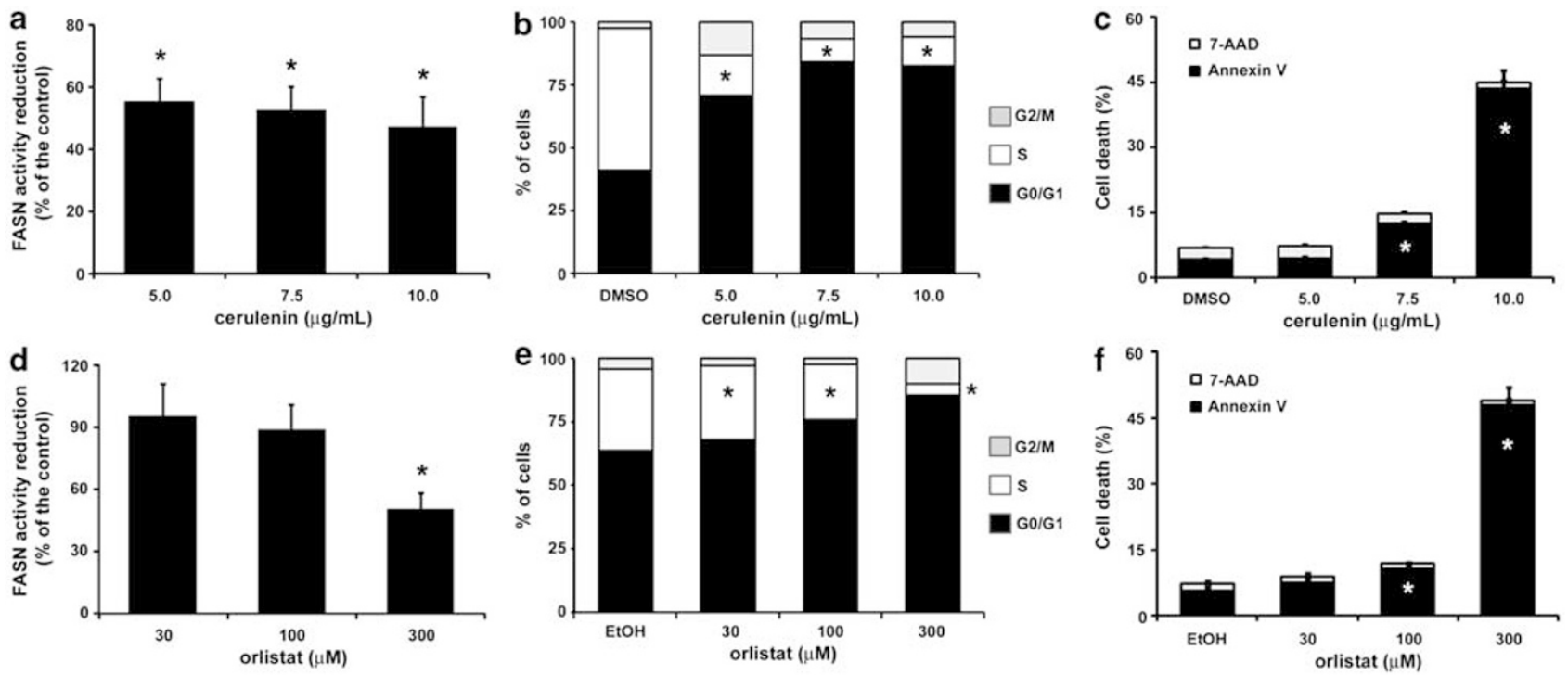

Figure 2 FASN inhibition reduces cell-cycle progression and induces apoptosis in B16-F10 melanoma cells. B16-F10 cells were treated with increasing concentrations of cerulenin or orlistat for $6 \mathrm{~h}$, and lipogenesis was analyzed by incorporation of $\left[{ }^{3} \mathrm{H}\right]$ water $(\mathbf{a}$ and $\mathbf{d})$; the percentages of cells in each phase of the cell cycle ( $\mathbf{b}$ and $\mathbf{e}$ ) and in apoptosis or necrosis (c and $\mathbf{f}$ ) were determined by flow cytometry after cerulenin or orlistat treatment for 24 or $48 \mathrm{~h}$, respectively. Values are mean \pm s.e.m. of at least 3 independent experiments. ${ }^{\star}$ Significantly different from control at $P<0.05$ level, Student's $t$-test.
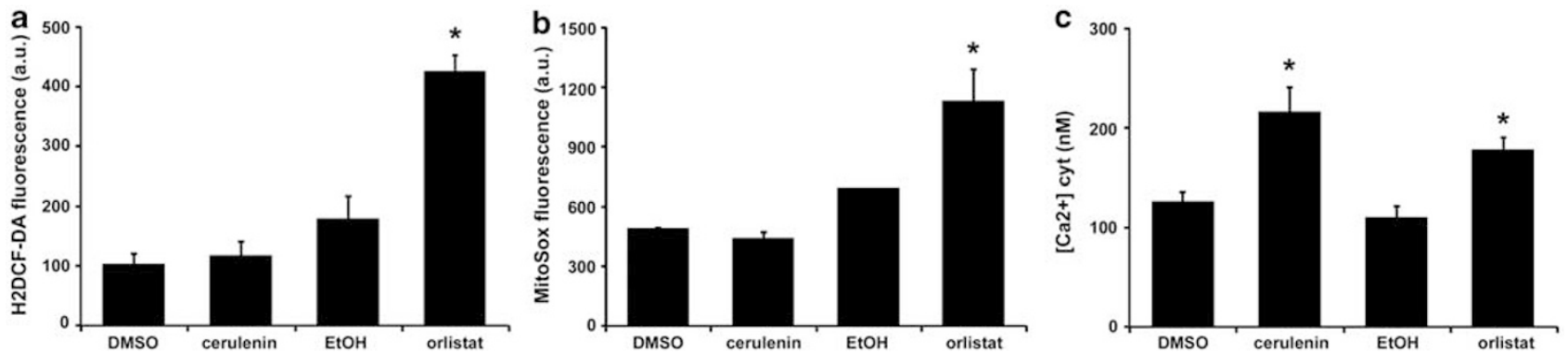

Figure 3 FASN inhibition with orlistat promotes oxidative stress and both orlistat and cerulenin increases $\left[\mathrm{Ca}^{2+}\right]_{\mathrm{cyt}}$ in B16-F10 melanoma cells. B16-F10 cells were treated with $10 \mu \mathrm{g} / \mathrm{ml}$ cerulenin or $300 \mu \mathrm{M}$ orlistat for $6 \mathrm{~h}$, washed and then probed with $3 \mu \mathrm{M} \mathrm{H}$ DCF-DA (a), $5 \mu \mathrm{M}$ MitoSox (b), or $3 \mu \mathrm{M}$ Fluo3-AM (c). $\mathrm{ROS}$ and $\left[\mathrm{Ca}^{2+}\right]_{\text {cyt }}$ production were analyzed using flow cytometry. Values are mean \pm s.e.m. of at least 5 independent experiments. ${ }^{*}$ Significantly different from control at $P<0.05$ level, Student's $t$-test.

Figure 4 FASN inhibition triggers cytochrome $c$ release and caspase- 9 and -3 activation in B16-F10 melanoma cells. (a) B16-F10 cells were treated with $10 \mu \mathrm{g} / \mathrm{ml}$ cerulenin or $300 \mu \mathrm{M}$ orlistat for 12 and $24 \mathrm{~h}$, respectively, and cytosolic cytochrome c release detected by ELISA. Citrate synthase activity used to confirm the absence of mitochondria in the cytosolic fractions after centrifugation (b). (c and d) Cytochrome $c$ release was also confirmed by flow cytometry, after anti-cytochrome $c$ staining. I-IV are controls: (I) negligible fluorescence of unlabeled cells, (II) background fluorescence of cells labeled with the secondary antibody, (III) fluorescence of cells incubated with both primary and secondary antibodies with no added digitonin, (IV) fluorescence of control cells permeabilized with $0.0001 \%$ digitonin, and incubated with both primary and secondary antibodies. (V-VII) Fluorescence of cerulenin or orlistat-treated cells permeabilized with digitonin and incubated with both antibodies. Note the decrease of the highly fluorescent cell population in the right region of the histograms and the increase of the nonfluorescent cell population in the left region after the treatment with cerulenin or orlistat and siRNA for FASN. Histograms are representative of three independent experiments. (VIII) Western-blotting reaction showing FASN protein knockdown by specific siRNAs after $72 \mathrm{~h}$. (e) Caspase-3 activation was determined by flow cytometry using FITC-DEVD-FMK after 18 and $36 \mathrm{~h}$ of treatment with cerulenin or orlistat, respectively. ( $\mathbf{f}$ and $\mathbf{g}$ ) Caspase- 9 and -8 activities were determined by measuring the fluorescences of free pnitroanilide and free AFC, respectively, as described for caspase-3. Values are mean \pm s.e.m. of at least three independent experiments. ${ }^{\star}$ Significantly different from control at $P<0.05$ level, Student's $t$-test. 
a

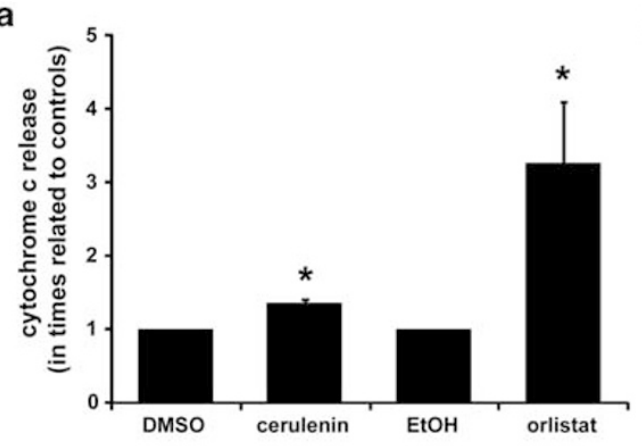

C

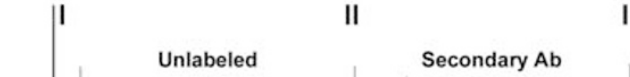

b

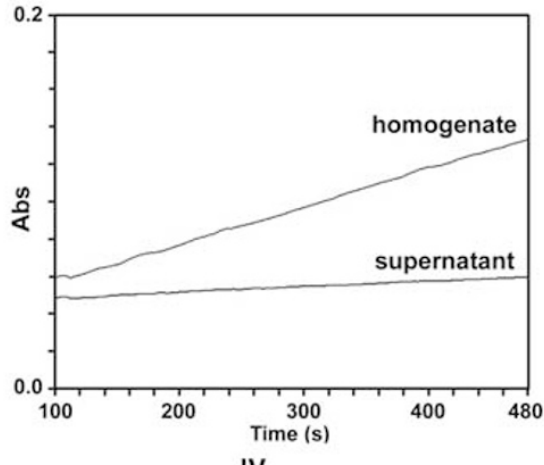

III

IV

$\begin{array}{ll}\text { Without digitonin } & \text { Digitonin }\end{array}$

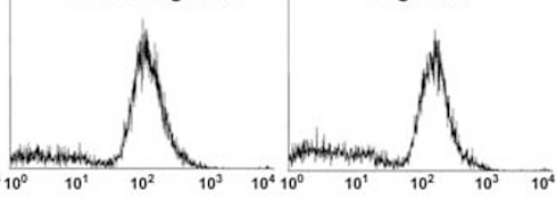

VII

VI

ह

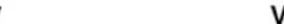

$\square$ DMso

$\square$ cerulenin

$\square$ EtOH

$\square$ orlistat

Control siRNA

VIII

FASN SiRNA

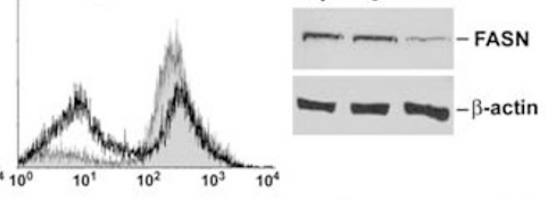

FITC fluorescence
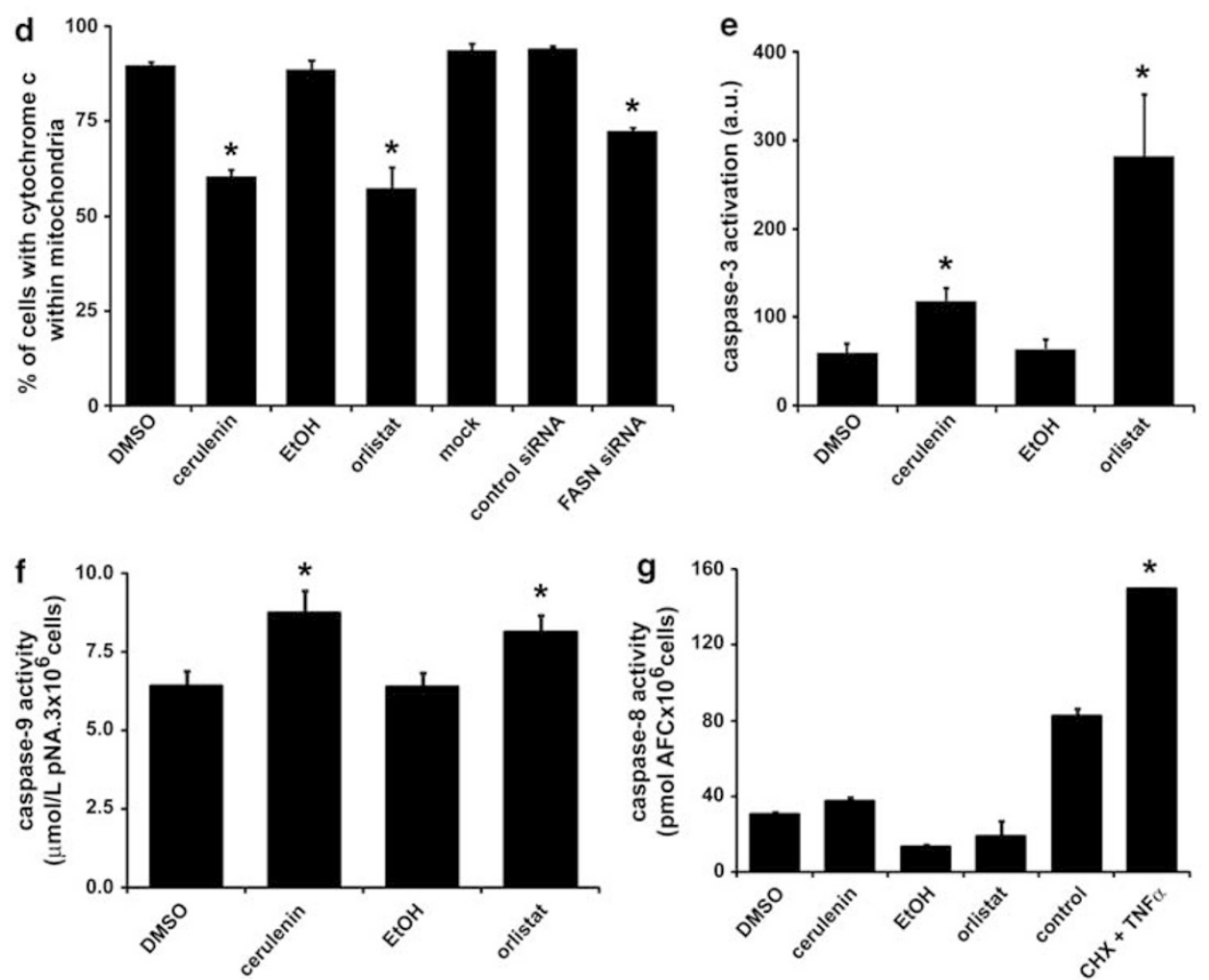

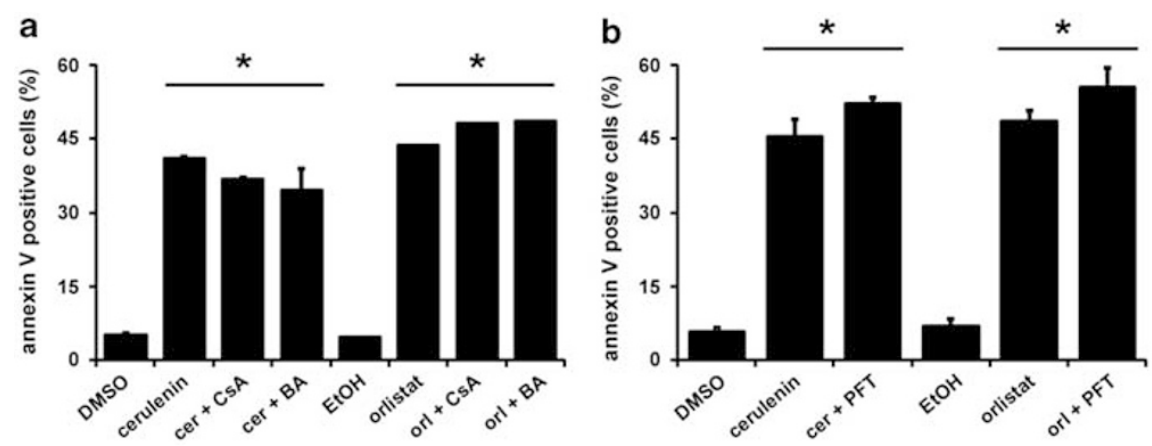

Figure 5 FASN inhibition-induced apoptosis is independent on MPT or p53 in B16-F10 melanoma cells. B16-F10 cells were treated with $10 \mu \mathrm{g} / \mathrm{ml}$ of cerulenin or $300 \mu \mathrm{M}$ of orlistat for 24 and $48 \mathrm{~h}$, respectively, in the presence of (a) cyclosporine $\mathrm{A}(\mathrm{CsA}, 1 \mu \mathrm{M})$, bongkrekic acid (BA, $0.5 \mu \mathrm{M})$, or (b) pifithrinalpha (PFT, $10 \mu \mathrm{M})$; the percentages of apoptotic cells were determined by flow cytometry. Values are mean \pm s.e.m. of at least three independent experiments. ${ }^{*}$ Significantly different from control at $P<0.05$ level, Student's $t$-test.

pathway of apoptosis following FASN protein knockdown in melanoma cells. Despite the differences in the relative amount of cytochrome $c$ release observed in Figures $4 \mathrm{a}$ and c, taken together the data strongly suggest that both drugs promote cytochrome $c$ release from the mitochondria of B16-F10 cells. Cytochrome $c$ is known to activate several apoptotic factors, including caspase-3. Indeed, the treatment of cultured melanoma cells with cerulenin or orlistat caused 2 and 4.4-fold increase, respectively, in caspase- 3 activation (Figure 4e). Cerulenin and orlistat were also able to activate caspase- 9 , but not -8 , initiators of the intrinsic and extrinsic pathways of apoptosis, respectively (Figures $4 \mathrm{f}$ and $\mathrm{g}$ ). Cytochrome $c$ can be released through $\mathrm{MPT}^{34}$ or the mitochondrial outer membrane permeabilization coordinated by Bcl-2 family members. ${ }^{39,40}$ Therefore, to assess the role of these mechanisms in the release of cytochrome $c$ depicted in Figure 4, we next incubated B16-F10 cells with cerulenin or orlistat in the presence of the MPT inhibitors cyclosporine A and bongkrekic acid. However, these compounds did not protect B16-F10 cells from FASN inhibition-induced apoptosis (Figure 5a).

As p53 activation has been associated with the FASN inhibition-induced apoptosis in colon carcinoma, neuroblastoma, and breast cancer cell lines, ${ }^{22,27}$ we sought to verify the effect of pifithrin-alpha, an inhibitor of p53 activation, on the apoptotic rates of B16-F10 cells. In the studied conditions, apoptosis was not prevented by p53 inhibition (Figure $5 \mathrm{~b}$ ), indicating that this tumor suppressor protein is not involved in the apoptosis triggered by the lack of an efficient endogenous fatty acid synthesis.

\section{DISCUSSION}

Cancer cells synthesize most of their fatty acids de novo, and the inhibition of the main lipogenic enzyme FASN clearly reduces proliferation at the same time that enhances the apoptotic rates of human and mouse melanoma cells. ${ }^{4,29,41}$ In the present study, we demonstrated that FASN inhibition induced the intrinsic pathway of apoptosis in B16-F10 mouse melanoma cells, which was preceded by an increase in both ROS production and cytosolic calcium concentration. In addition, this apoptotic cell death was not dependent on p53 activation or MPT.

The pharmacological inhibition of FASN reduces the proliferation and promotes cell death in several tumor cell lines. ${ }^{20-23}$ The cell cycle arrest that follows FASN blockage is associated with increased levels of p21 and p53 in colon, breast, gastrointestinal, and human melanoma tumor cells. $^{22,41-43}$ Indeed, ongoing experiments from our laboratory have shown that cerulenin or orlistat significantly increase p21 protein amount in B16-F10 cell lysates. In this study, we detected a significant increase in annexin V-positive cells, cytochrome $c$ release, and caspase- 9 and -3 activation, which collectively confirm that FASN inhibition promotes apoptosis. ${ }^{44}$ Necrotic cells were not found and despite the previous data showing rapid and reversible autophagy in gastric tumor cells induced by orlistat, ${ }^{19}$ we did not detect acidic vesicular organelles in our treated melanoma cells.

To better understand the pathway responsible for the apoptosis produced by specific FASN blockage, we searched for the early events that precede the programmed cell death. Indeed, after a short period incubation with orlistat B16-F10 melanoma cells showed increased levels of ROS, and both orlistat and cerulenin were able to enhance cytosolic calcium concentrations. The biological mechanisms that underlie the differences in ROS levels in B16-F10 cells may be related to a non-FASN inhibitory effect of orlistat. In fact, high concentrations of cerulenin significantly decrease protein acylation, which is particularly evident in glucose-stimulated insulin secretion. ${ }^{45}$ In contrast, FASN silencing was previously shown to increase ROS levels and to promote mitochondrial membrane collapse in breast and prostate cancer cells. ${ }^{46,47}$ $\left[\mathrm{Ca}^{2+}\right]_{\text {cyt }}$ elevations may result in the activation of calcineurin ${ }^{48}$ that promotes $\mathrm{BAD}$ activation and apoptosis through the intrinsic pathway independently of MPT. ${ }^{49}$ However, further studies are necessary to elucidate the origin of $\left[\mathrm{Ca}^{2+}\right]_{\mathrm{cyt}}$ elevation induced by FASN inhibition in melanoma cells. 
It is interesting that, we observed that FASN inhibition significantly changes the mitochondrial free fatty acid composition (Zecchin KG, unpublished results). Increased ROS generation and cytosolic $\mathrm{Ca}^{2+}$ concentration may also result in MPT, ${ }^{50}$ phenomenon that was excluded in our studies, as MPT inhibitors as cyclosporine A and bongkrekic acid did not protect melanoma cells from FASN inhibition-induced apoptosis.

FASN inhibition leads to the accumulation of malonylCoA, which is cytotoxic and inhibits carnitine palmitoyltransferase- 1 and fatty acid oxidation. ${ }^{26,51-53}$ Reduced carnitine palmitoyltransferase-1 interaction with the antiapoptotic protein $\mathrm{Bcl}-2^{54}$ or palmitoyltransferase-1 inhibition-induced accumulation of ceramide, a sphingolipid implicated in apoptosis through death inducers and the extrinsic pathway of apoptosis, ${ }^{26}$ were previously suggested to explain the pro-apoptotic effect of FASN blockage. The results in this study presented show activation of the intrinsic pathway of apoptosis by the release of cytochrome $c$ from B16-F10 melanoma cell mitochondria following FASN chemical inhibition or knockdown, which was associated with caspase- 9 and -3 activation in agreement with previous findings. ${ }^{27,28,41,55}$ As the cytochrome $c$ release was not related to MPT in our experiments, malonyl-CoA accumulation, palmitoyltransferase-1 inhibition, and Bcl-2 may be involved in this process. It has been shown that colon and breast cancer cells are more resistant to FASN blockage and malonyl-CoA accumulation when p53 is intact. ${ }^{22}$ However, despite the fact that B16-F10 cells have wild-type $\mathrm{p} 53,{ }^{56}$ in the present study we demonstrate that its inhibition with pifithrin-alpha did not reduce apoptotic rates and indicate that apoptosis after FASN inhibition is p53-independent.

In conclusion, FASN inhibition with cerulenin or orlistat reduces cell growth and induces apoptosis in B16-F10 melanoma cells. Cell death was accompanied by cytochrome $c$ release and caspase- 9 and -3 activation, but independent on MPT or p53 activation. The absence of MPT suggests that cytochrome $c$ release may be related to Bcl-2 family involvement. In addition, orlistat-induced apoptosis was preceded by oxidative stress, as demonstrated by increased ROS and increased cytosolic calcium concentration. Taken together, our results show the involvement of mitochondria in FASN inhibition-induced apoptosis in murine melanoma cells.

\section{ACKNOWLEDGEMENTS}

The authors thank Dr Nadja C de Souza-Pinto for providing cycloheximide and tumor necrosis factor $\alpha$. This work was supported by Fundação de Amparo à Pesquisa do Estado de São Paulo (FAPESP—07/54639-1 and 08/57471-7), Coordenação de Aperfeiçoamento de Pessoal de Nível Superior (CAPES), and Conselho Nacional de Desenvolvimento Científico e Tecnológico (CNPq-470539/2008-9).

\section{DISCLOSURE/CONFLICT OF INTEREST}

The authors declare no conflict of interest.
1. Smith $\mathrm{S}$. The animal fatty acid synthase: one gene, one polypeptide, seven enzymes. FASEB J 1994;8:1248-1259.

2. Menendez JA, Lupu R. Fatty acid synthase and the lipogenic phenotype in cancer pathogenesis. Nat Rev Cancer 2007;7:763-777.

3. Brink J, Ludtke SJ, Yang CY, et al. Quaternary structure of human fatty acid synthase by electron cryomicroscopy. Proc Natl Acad Sci USA 2002;99:138-143.

4. Weiss L, Hoffmann GE, Schreiber R, et al. Fatty-acid biosynthesis in man, a pathway of minor importance. Purification, optimal assay conditions, and organ distribution of fatty-acid synthase. Biol Chem Hoppe Seyler 1986;367:905-912.

5. Kuhajda FP. Fatty-acid synthase and human cancer: new perspectives on its role in tumor biology. Nutrition 2000;16:202-208.

6. Alo $\mathrm{PL}$, Visca $\mathrm{P}$, Framarino $\mathrm{ML}$, et al. Immunohistochemical study of fatty acid synthase in ovarian neoplasms. Oncol Rep 2000;7: 1383-1388.

7. Pizer ES, Jackisch C, Wood FD, et al. Inhibition of fatty acid synthesis induces programmed cell death in human breast cancer cells. Cancer Res 1996;56:2745-2747.

8. Pizer ES, Wood FD, Heine HS, et al. Inhibition of fatty acid synthesis delays disease progression in a xenograft model of ovarian cancer. Cancer Res 1996;56:1189-1193.

9. Gansler TS, Hardman III W, Hunt DA, et al. Increased expression of fatty acid synthase (OA-519) in ovarian neoplasms predicts shorter survival. Hum Pathol 1997;28:686-692.

10. Dhanasekaran SM, Barrette TR, Ghosh D, et al. Delineation of prognostic biomarkers in prostate cancer. Nature 2001;412:822-826.

11. Swinnen JV, Roskams T, Joniau S, et al. Overexpression of fatty acid synthase is an early and common event in the development of prostate cancer. Int J Cancer 2002;98:19-22.

12. Innocenzi $D$, Alo $P L$, Balzani $A$, et al. Fatty acid synthase expression in melanoma. J Cutan Pathol 2003;30:23-28.

13. Rossi $S$, Graner E, Febbo P, et al. Fatty acid synthase expression defines distinct molecular signatures in prostate cancer. Mol Cancer Res 2003;1:707-715.

14. Takahiro T, Shinichi K, Toshimitsu S. Expression of fatty acid synthase as a prognostic indicator in soft tissue sarcomas. Clin Cancer Res 2003;9:2204-2212.

15. Visca P, Sebastiani V, Botti C, et al. Fatty acid synthase (FAS) is a marker of increased risk of recurrence in lung carcinoma. Anticancer Res 2004;24:4169-4173.

16. Kapur $P$, Rakheja $D$, Roy $L C$, et al. Fatty acid synthase expression in cutaneous melanocytic neoplasms. Mod Pathol 2005;18:1107-1112.

17. van de Sande T, Roskams T, Lerut E, et al. High-level expression of fatty acid synthase in human prostate cancer tissues is linked to activation and nuclear localization of Akt/PKB. J Pathol 2005;206:214-219.

18. Rossi S, Ou W, Tang D, et al. Gastrointestinal stromal tumours overexpress fatty acid synthase. J Pathol 2006;209:369-375.

19. Dowling S, Cox J, Cenedella RJ. Inhibition of fatty acid synthase by Orlistat accelerates gastric tumor cell apoptosis in culture and increases survival rates in gastric tumor bearing mice in vivo. Lipids 2009;44:489-498.

20. Furuya $\mathrm{Y}$, Akimoto $\mathrm{S}$, Yasuda $\mathrm{K}$, et al. Apoptosis of androgenindependent prostate cell line induced by inhibition of fatty acid synthesis. Anticancer Res 1997;17:4589-4593.

21. Pizer ES, Chrest FJ, DiGiuseppe JA, et al. Pharmacological inhibitors of mammalian fatty acid synthase suppress DNA replication and induce apoptosis in tumor cell lines. Cancer Res 1998;58:4611-4615.

22. Li JN, Gorospe M, Chrest FJ, et al. Pharmacological inhibition of fatty acid synthase activity produces both cytostatic and cytotoxic effects modulated by p53. Cancer Res 2001;61:1493-1499.

23. Zhou W, Han WF, Landree LE, et al. Fatty acid synthase inhibition activates AMP-activated protein kinase in SKOV3 human ovarian cancer cells. Cancer Res 2007;67:2964-2971.

24. Kridel SJ, Axelrod F, Rozenkrantz N, et al. Orlistat is a novel inhibitor of fatty acid synthase with antitumor activity. Cancer Res 2004;64: 2070-2075.

25. Alli PM, Pinn ML, Jaffee EM, et al. Fatty acid synthase inhibitors are chemopreventive for mammary cancer in neu-N transgenic mice. Oncogene 2005;24:39-46.

26. Bandyopadhyay $S$, Zhan R, Wang $Y$, et al. Mechanism of apoptosis induced by the inhibition of fatty acid synthase in breast cancer cells. Cancer Res 2006;66:5934-5940. 
27. Heiligtag SJ, Bredehorst R, David KA. Key role of mitochondria in cerulenin-mediated apoptosis. Cell Death Differ 2002;9:1017-1025.

28. Liu X, Shi Y, Giranda VL, et al. Inhibition of the phosphatidylinositol 3-kinase/Akt pathway sensitizes MDA-MB468 human breast cancer cells to cerulenin-induced apoptosis. Mol Cancer Ther 2006;5:494-501.

29. Carvalho MA, Zecchin KG, Seguin F, et al. Fatty acid synthase inhibition with Orlistat promotes apoptosis and reduces cell growth and lymph node metastasis in a mouse melanoma model. Int J Cancer 2008;123:2557-2565.

30. Knowles LM, Axelrod F, Browne CD, et al. A fatty acid synthase blockade induces tumor cell-cycle arrest by down-regulating Skp2. J Biol Chem 2004:279:30540-30545.

31. Chen Y, McMillan-Ward E, Kong J, et al. Oxidative stress induces autophagic cell death independent of apoptosis in transformed and cancer cells. Cell Death Differ 2008;15:171-182.

32. LeBel CP, Ischiropoulos $\mathrm{H}$, Bondy SC. Evaluation of the probe $2^{\prime}$, $7^{\prime}$-dichlorofluorescin as an indicator of reactive oxygen species formation and oxidative stress. Chem Res Toxicol 1992:5:227-231.

33. Payne CM, Weber C, Crowley-Skillicorn C, et al. Deoxycholate induces mitochondrial oxidative stress and activates NF-kappaB through multiple mechanisms in HCT-116 colon epithelial cells. Carcinogenesis 2007;28:215-222.

34. Zecchin KG, Seidinger AL, Chiaratti MR, et al. High Bcl-2/Bax ratio in Walker tumor cells protects mitochondria but does not prevent $\mathrm{H}_{2} \mathrm{O}_{2}$ induced apoptosis via calcineurin pathways. J Bioenerg Biomembr 2007;39:186-194.

35. Tsien RY. Fluorescence measurement and photochemical manipulation of cytosolic free calcium. Trends Neurosci 1988;11:419-424.

36. Abou-Khalil S, Abou-Khalil WH, Planas L, et al. Interaction of rhodamine 123 with mitochondria isolated from drug-sensitive and -resistant Friend leukemia cells. Biochem Biophys Res Commun 1985;127: 1039-1044.

37. Shepherd D, Garland PB. ATP controlled acetoacetate and citrate synthesis by rat liver mitochondria oxidising palmitoyl-carnitine, and the inhibition of citrate synthase by ATP. Biochem Biophys Res Commun 1966;22:89-93.

38. Campos CB, Paim BA, Cosso RG, et al. Method for monitoring of mitochondrial cytochrome $c$ release during cell death: Immunodetection of cytochrome $\mathrm{c}$ by flow cytometry after selective permeabilization of the plasma membrane. Cytometry Part A 2006;69: 515-523.

39. Green DR, Reed JC. Mitochondria and apoptosis. Science 1998; 281:1309-1312.

40. Garrido C, Galluzzi L, Brunet M, et al. Mechanisms of cytochrome c release from mitochondria. Cell Death Differ 2006;13:1423-1433.

41. Ho TS, Ho YP, Wong WY, et al. Fatty acid synthase inhibitors cerulenin and $\mathrm{C} 75$ retard growth and induce caspase-dependent apoptosis in human melanoma A-375 cells. Biomed Pharmacother 2007:61: 578-587.

42. Menendez JA, Vellon L, Lupu R. Antitumoral actions of the anti-obesity drug orlistat (XenicalTM) in breast cancer cells: blockade of cell cycle progression, promotion of apoptotic cell death and PEA3-mediated transcriptional repression of Her2/neu (erbB-2) oncogene. Ann Oncol 2005;16:1253-1267.

43. Menendez JA, Vellon L, Lupu R. Orlistat: from antiobesity drug to anticancer agent in Her-2/neu (erbB-2)-overexpressing gastrointestinal tumors? Exp Biol Med (Maywood) 2005;230:151-154.

44. Kroemer G, Galluzzi L, Vandenabeele P, et al. Classification of cell death: recommendations of the Nomenclature Committee on Cell Death 2009. Cell Death Differ 2009;16:3-11.

45. Straub SG, Sharp GWG. Inhibition of insulin secretion by cerulenin might be due to impaired glucose metabolism. Diabetes Metab Res Rev 2007:23:146-151.

46. Chajes V, Cambot M, Moreau K, et al. Acetyl-CoA carboxylase alpha is essential to breast cancer cell survival. Cancer Res 2006;66:5287-5294.

47. Migita $T$, Ruiz $S$, Fornari $A$, et al. Fatty acid synthase: a metabolic enzyme and candidate oncogene in prostate cancer. J Natl Cancer Inst 2009;101:519-532.

48. Lotem J, Kama R, Sachs L. Suppression or induction of apoptosis by opposing pathways downstream from calcium-activated calcineurin. Proc Natl Acad Sci USA 1999;96:12016-12020.

49. Wang HG, Pathan N, Ethell IM, et al. Ca2+-induced apoptosis through calcineurin dephosphorylation of BAD. Science 1999;284: 339-343.

50. Kowaltowski AJ, Castilho RF, Vercesi AE. Mitochondrial permeability transition and oxidative stress. FEBS Lett 2001:495:12-15.

51. Pizer ES, Thupari J, Han WF, et al. Malonyl-coenzyme-A is a potential mediator of cytotoxicity induced by fatty-acid synthase inhibition in human breast cancer cells and xenografts. Cancer Res 2000;60: 213-218.

52. Thupari JN, Pinn ML, Kuhajda FP. Fatty acid synthase inhibition in human breast cancer cells leads to malonyl-CoA-induced inhibition of fatty acid oxidation and cytotoxicity. Biochem Biophys Res Commun 2001:285:217-223

53. Zhang Y, Guo C, Yu G. A pilot study of fatty acid metabolism in oral squamous cell carcinoma. Int J Oral Maxillofac Surg 2005;34:78-81.

54. Paumen $M B$, Ishida $\mathrm{Y}$, Han $\mathrm{H}$, et al. Direct interaction of the mitochondrial membrane protein carnitine palmitoyltransferase I with BCl-2. Biochem Biophys Res Commun 1997:231:523-525.

55. Uddin S, Siraj AK, Al-Rasheed M, et al. Fatty acid synthase and AKT pathway signaling in a subset of papillary thyroid cancers. J Clin Endocrinol Metab 2008;93:4088-4097.

56. Mo $\mathrm{H}$, Elson $\mathrm{CE}$. Apoptosis and cell-cycle arrest in human and murine tumor cells are initiated by isoprenoids. J Nutr 1999;129:804-813. 